\title{
Dietary nutrient intake of Korean adolescent distance runners
}

\author{
Sun-Hyo Kim', Chang-Suk Oh², Jae-Hyun Lee ${ }^{3, *}$ \\ 'Department of Technology and Home Economics Education, Kongju National University, Gongju, Korea \\ ${ }^{2}$ Department of Exercise Prescription, Baekseok University, Cheonan, Korea \\ ${ }^{3}$ Department of Sports Science \& Rehabilitation, Woosong University, Daejeon, Korea
}

This study examined the dietary nutrient intake of Korean adolescent distance runners and analyzed the difference between weekdays and weekends. The participants were 40 male middle- and long-distance runners aged 13 to 18 years, 36 of whom were analyzed. The 3-day diet records including 2 weekdays and 1 weekend day, were investigated according to the food record method and analyzed using the computer-aided nutritional analysis program. A paired t-test was used to compare the energy and nutrient intakes of the weekdays and weekends, and the chi-square test was used to compare the distribution of the nutrient intake below the estimated average requirement. The results showed that the energy intake per day was quite low at 2,051.0 \pm 304.3 $\mathrm{kcal}$, with a body mass index percentile of $16.8 \pm 9.8$. The nutrients that showed remarkably lower levels than the dietary reference intakes for Koreans were vitamin $D$, vitamin $C$, vitamin $B_{2}$, and calcium, among which calcium was the highest at $86.1 \%$ in the proportion of those who consumed less than the estimated average requirement. The intakes of vitamin $\mathrm{C}$ and calcium, in particular, showed a significant decrease during the weekends. Therefore, to improve the dietary nutrient intake of adolescent male runners, appropriate management of the weekend diet as well as school meals should be considered.

Keywords: Nutritional status, Running, Adolescence, Growth

\section{INTRODUCTION}

The dietary plans for adolescent athletes should be focused on the needs of both performance and growth (Aerenhouts et al., 2011; Petrie et al., 2004). Excessive training without meeting the nutritional requirements during growth carries the risks of irreversible injury or growth inhibition, such as delayed puberty, poor bone health, short stature, and increased risk of injury (Meyer et al., 2007; Solomon et al., 2017). To prevent these problems and optimize the performance, the athletes of middle- and long-distance running, which require a large amount of energy for the training and competition, should be managed so they do not lack energy in their daily meals. In addition, growing athletes should also be free from a lack of protein and minerals required for the development of the musculoskeletal system, and replenishment of micronutrients that are lost in strenuous training should not be overlooked.
Adolescent athletes, however, often report lower energy and calcium intakes than the recommended daily amounts (Aerenhouts et al., 2011; Gibson et al., 2011; Juzwiak et al., 2008; Martínez et al., 2011). The lack of energy or calcium intake can negatively affect the growth of athletes in adolescence, who require the most energy and calcium among all life courses because of their rapid growth rates. In this regards, the Sports Dietitians Australia Position Statement (Desbrow et al., 2014) suggested that the indicators of growth and development should be monitored and compared with the growth standards to determine if the adolescents' energy intake is adequate. In particular, a lack of energy intake is likely to lead to a deficiency of other nutrients, further highlighting the need for improvement.

The difference in eating patterns between weekdays and weekends is easily overlooked when monitoring and devising improvements for the nutritional status of these athletes. Most of the youth
${ }^{\star}$ Corresponding author: Jae-Hyun Lee (D) https://orcid.org/0000-0003-2749-2909 Department of Sports Science \& Rehabilitation, Woosong University,

171 Dongdaejeon-ro, Dong-gu, Daejeon 34606, Korea

E-mail: leejh1215@gmail.com

Received: October 7, 2019 / Accepted: November 22, 2019
This is an Open Access article distributed under the terms of the Creative Commons Attribution Non-Commercial License (http://creativecommons.org/licenses/by-nc/4.0/) which permits unrestricted non-commercial use, distribution, and reproduction in any medium, provided the original work is properly cited. 
athletes stay at school during the weekdays, eating school meals, and return home on the weekends to eat at home or out.

Therefore, this study compared the consumption of energy and nutrients to the dietary reference intakes for Koreans (KDRI) in male adolescent middle- and long-distance athletes, with an analysis of the differences in the energy and nutrient intakes between weekdays and weekends. In addition, the percentiles of height, weight, and body mass index (BMI), which were derived using the reference values from Korea Centers for Disease Control and Prevention, were obtained. The purpose of this study was to investigate the nutritional status of middle- and long-distance male adolescent runners as a basis to establish effective dietary strategies for improving both their athletic performance and healthy growth.

\section{MATERIALS AND METHODS}

\section{Participants}

The study participants were 13 to 18 years old adolescent male middle- and long-distance runners who belonged to a physical education school. They were registered in the Korea Association of Athletics Federations. The participants were in the training period and the athletes who were required to compete during the survey were excluded. The runners who could not maintain ordinary eating patterns due to participating in special events were also excluded. The Ethics Committee of Kongju National University (KNU_IRB_2019-07) approved this study. Prior to the investigation, the athletes and their parents were given a detailed explanation of the background, objectives, and procedures of the study and consented to participate in the study with documents.

The number of participants for this study was calculated using G-power. The sample size was 34 participants with an effect size, alpha value, and power of $0.5,0.05$, and 0.8 respectively. Based on these results, 40 participants were recruited, and only 36 athletes were analyzed due to measurement errors and some unanswered surveys.

\section{Anthropometric measurements}

The anthropometric data consisting of height and weight were self-reported by the athletes and confirmed by their coaches. The BMI was calculated as the body weight in kilograms divided by the square of the body height in meters $\left(\mathrm{kg} / \mathrm{m}^{2}\right)$. As the athletes are in the process of growth, the percentiles of height, weight, and BMI were calculated based on the 2017 Growth Chart released by the Korea Centers for Disease Control and Prevention (https://kn- hanes.cdc.go.kr/knhanes/eng).

\section{Dietary intake data collection}

The dietary intake data were collected using the food record method during 3 days including 2 weekdays and 1 weekend day. The participants instructed on how to record their dietary intake information on dietary sheets by a researcher and asked to complete the sheets for 3 days. The completed dietary records were confirmed and revised by a researcher and trained staff interviewing participants. The diet records of weekdays were checked with the school meal menu provided by school dietitians. Incomplete or unreasonable records were excluded from the data set for analysis.

\section{Energy and nutrients intake evaluation}

All nutrient intakes were calculated using the computer-aided nutritional analysis program (CAN-Pro 4.0, Korean Nutrition Society, Seoul, Korea). The daily average energy intake and nutrients intakes were calculated, and the average weekdays and weekends values were presented separately. The nutrients to be analyzed were carbohydrates, fats, proteins, vitamins (vitamin A, vitamin $\mathrm{D}$, vitamin $\mathrm{E}$, vitamin $\mathrm{C}$, vitamin $\mathrm{B}_{1}$, vitamin $\mathrm{B}_{2}$, niacin, and folic acid), and minerals (calcium, phosphorus, iron, and zinc).

The energy and nutrient intakes were compared with the ageand gender-specific values of the KDRI to evaluate their adequacy (Ministry of Health and Welfare, Korean Nutrition Society, 2015). The estimated energy requirements (EER), which is used to evaluate the adequacy of the energy intake, were derived with the low active coefficient reflecting the general level of physical activity of Koreans (Ministry of Health and Welfare, Korean Nutrition Society, 2015). The EER for very active level was also used to evaluate the adequacy of the energy intake of athletes. It was calculated as follows using the coefficient for very active level (1.42) (Ministry of Health and Welfare, Korean Nutrition Society, 2015).

EER for male adolescents $=88.5-61.9 \times$ age $(\mathrm{yr})$

$$
+1.42(26.7 \times \text { weight }[\mathrm{kg}] \times 903 \times \text { height }[\mathrm{m}])+25 \mathrm{kcal} / \text { day }
$$

*Physical activity index for very active level, 1.42, was used as a coefficient in this equation.

The energy intake by carbohydrates, fats, and proteins was evaluated using the reference of the acceptable macronutrient distribution range proposed by the 2015 KDRI (Ministry of Health and Welfare, Korean Nutrition Society, 2015) and the percentages of the athletes whose intakes of nutrients were less than the esti- 
mated average requirement (EAR) were also calculated.

\section{Data analysis}

The descriptive data were expressed as the mean values with standard deviations for continuous variables. A paired $t$-test was used to compare the energy and nutrient intakes of weekdays and weekends. A chi-square test was used to compare the distribution of consumption below the EAR. A Fisher exact test was applied to test the significance if the cells with frequencies of five or fewer were more than $20 \%$ of the total.

All statistical analyses were conducted using IBM SPSS Statistics ver. 24.0 (IBM Co., Armonk, NY, USA) and $P<0.05$ was considered significant.

\section{RESULTS}

The physical growth status evaluated as the percentiles of height, weight, and BMI showed that the adolescent male middle- and long-distance athletes were very skinny (Table 1 ). Their height percentile was almost the median, while the weight and BMI were very low.

The average energy intake was $2051.0 \pm 304.3 \mathrm{kcal} /$ day, corresponding to $77.9 \% \pm 12.8 \%$ of the EER reflecting low active level and only $60.7 \% \pm 13.0 \%$ of the EER reflecting very active level (Table 2). The energy intake of weekdays was significantly higher than that of weekends. The energy intake rates of carbohydrates, fats, and proteins were $60.4 \%, 23.9 \%$, and $15.7 \%$, respectively, which were within the acceptable macronutrient distribution range suggested by the $2015 \mathrm{KDRI}$.
The nutrients that showed a significant difference between weekdays and weekends were vitamin A, vitamin C, calcium, and phosphorus with a higher intake during the weekdays than weekends $(P<0.05)$ (Table 3).

The intakes of vitamin $\mathrm{D}$, vitamin $\mathrm{C}$, vitamin $\mathrm{B}_{2}$, and calcium were much lower than the KDRI, while the ratio of the measured intakes of vitamin $\mathrm{C}$, calcium, and phosphorus compared to the reference values differed between weekdays and weekends $(P<0.05)$ (Table 4).

The nutrients that more than $50 \%$ of athletes consumed below the EAR were vitamin $\mathrm{B}_{2}$ and calcium. No case of eating protein less than the EAR during weekdays was noted, but it increased significantly to $19.4 \%$ on weekends. Other nutrients that showed a significant increase in the percentage of athletes who consumed less than the EAR on weekends were vitamin $A$, vitamin $C$, phosphorus, $\mathrm{Fe}$, and $\mathrm{Zn}(P<0.05)$ (Table 5).

Table 1. Characteristics of study participants $(n=36)$

\begin{tabular}{lc}
\hline Variable & Mean \pm SD \\
\hline Age $(\mathrm{yr})$ & $16.0 \pm 1.5$ \\
Height $(\mathrm{cm})$ & $170.9 \pm 7.7$ \\
Height percentile ${ }^{\mathrm{a})}$ & $52.3 \pm 29.5$ \\
Weight $(\mathrm{kg})$ & $55.7 \pm 7.1$ \\
Weight percentile & $25.1 \pm 17.4$ \\
BMl $\left(\mathrm{kg} / \mathrm{m}^{2}\right)$ & $19.0 \pm 1.3$ \\
BMl percentile $^{\mathrm{a})}$ & $16.8 \pm 9.8$ \\
\hline
\end{tabular}

SD, standard deviation; BMl, body mass index.

a'The value was based on the 2017 Korean national growth charts for children and adolescents.

Table 2. Comparison of the energy and energy nutrient intakes during weekdays and weekends $(n=36)$

\begin{tabular}{|c|c|c|c|c|c|}
\hline Variable & Total & Weekdays & Weekends & $t$-value & $P$-value \\
\hline Energy intake (kcal/day) & $2,051.0 \pm 304.3$ & $2,123.1 \pm 377.8$ & $1,903.2 \pm 486.4$ & 2.178 & 0.036 \\
\hline Energy intake/EER ${ }_{1}^{\text {a) }}(\%)$ & $77.9 \pm 12.8$ & $80.6 \pm 15.0$ & $72.5 \pm 19.6$ & 2.162 & 0.038 \\
\hline Energy intake/EER ${ }^{\text {b) }}(\%)$ & $60.7 \pm 13.0$ & $62.8 \pm 14.8$ & $56.3 \pm 16.6$ & 2.200 & 0.035 \\
\hline Carbohydrate (g/day) & $307.8 \pm 48.3$ & $317.9 \pm 54.6$ & $287.5 \pm 79.8$ & 2.007 & 0.053 \\
\hline Fat (g/day) & $55.3 \pm 13.0$ & $57.9 \pm 18.1$ & $50.1 \pm 15.7$ & 1.934 & 0.061 \\
\hline Protein (g/day) & $81.2 \pm 15.1$ & $84.1 \pm 17.3$ & $75.0 \pm 29.9$ & 1.527 & 0.136 \\
\hline Protein intake/RNI (\%) & $136.3 \pm 32.7$ & $141.7 \pm 37.3$ & $125.5 \pm 51.1$ & 1.694 & 0.099 \\
\hline Energy taken by carbohydrate/ daily energy intake (\%) & $60.4 \pm 3.9$ & $61.1 \pm 5.9$ & $59.1 \pm 6.4$ & 1.220 & 0.231 \\
\hline Energy taken by fat/ daily energy intake (\%) & $23.9 \pm 3.6$ & $23.5 \pm 4.8$ & $24.9 \pm 5.7$ & -1.114 & 0.273 \\
\hline Energy taken by protein/ daily energy intake (\%) & $15.7 \pm 1.8$ & $15.5 \pm 1.6$ & $16.0 \pm 4.4$ & -0.617 & 0.541 \\
\hline
\end{tabular}

Values are presented as mean \pm standard deviation.

$\mathrm{RNI}$, recommended nutrient intake.

${ }^{a} E_{E} E R_{1}$, estimated energy requirements derived with the coefficient for low active level reflecting the general physical activity level of Koreans. ${ }^{b} E E R_{2}$, estimated energy requirements derived with the coefficient for very active level. 
Kim SH, et al. • Nutrient intake of adolescent distance runners

Table 3. Comparison of the nutrient intakes during weekdays and weekends $(n=36)$

\begin{tabular}{|c|c|c|c|c|c|}
\hline Nutrients & Total & Weekdays & Weekends & $t$-value & $P$-value \\
\hline Vitamin A ( $\mu \mathrm{g}$ RAE/day) & $965.6 \pm 353.4$ & $1061.3 \pm 470.4$ & $823.7 \pm 540.3$ & 2.096 & 0.043 \\
\hline Vitamin D ( $\mu \mathrm{g} /$ day) & $6.2 \pm 3.3$ & $6.1 \pm 3.3$ & $6.4 \pm 6.1$ & -0.311 & 0.757 \\
\hline Vitamin $\mathrm{E}$ (mg $\alpha$-TE/day) & $18.4 \pm 16.2$ & $20.7 \pm 23.9$ & $13.8 \pm 4.3$ & 1.753 & 0.088 \\
\hline Vitamin C (mg/day) & $85.9 \pm 31.0$ & $93.8 \pm 37.1$ & $70.3 \pm 33.2$ & 3.678 & 0.001 \\
\hline Vitamin $B_{1}(\mathrm{mg} /$ day) & $1.4 \pm 0.3$ & $1.5 \pm 0.4$ & $1.3 \pm 0.4$ & 1.368 & 0.180 \\
\hline Vitamin $B_{2}$ (mg/day) & $1.3 \pm 0.3$ & $1.4 \pm 0.4$ & $1.3 \pm 0.5$ & 0.966 & 0.341 \\
\hline Niacin (mg NE/day) & $18.4 \pm 3.3$ & $19.1 \pm 4.7$ & $16.9 \pm 7.0$ & 1.440 & 0.159 \\
\hline Folic acid ( $\mu \mathrm{g}$ DFE/day) & $471.6 \pm 113.8$ & $490.5 \pm 147.8$ & $432.7 \pm 148.3$ & 1.726 & 0.093 \\
\hline $\mathrm{Ca}$ (mg/day) & $582.2 \pm 182.7$ & $625.5 \pm 94.4$ & $500.0 \pm 278.4$ & 2.675 & 0.011 \\
\hline $\mathrm{P}(\mathrm{mg} /$ day $)$ & $1,188.5 \pm 221.9$ & $1,253.2 \pm 258.0$ & $1,061.4 \pm 445.3$ & 2.193 & 0.035 \\
\hline $\mathrm{Fe}$ (mg/day) & $16.9 \pm 4.4$ & $17.7 \pm 5.2$ & $15.4 \pm 6.8$ & 1.789 & 0.082 \\
\hline Zn (mg/day) & $12.3 \pm 2.5$ & $12.5 \pm 2.6$ & $12.1 \pm 5.5$ & 0.379 & 0.707 \\
\hline
\end{tabular}

Values are presented as mean \pm standard deviation.

RAE, retinol activity equivalents; $\alpha$-TE, $\alpha$-tocopherol equivalent; NE, niacin equivalent; DFE, dietary folate equivalent.

Table 4. Comparison of the nutrient intake ratio ${ }^{\text {a) }}$ between weekdays and weekends $(n=36)$

\begin{tabular}{|c|c|c|c|c|c|c|}
\hline Nutrients & Reference & Total & Weekdays & Weekends & $t$-value & $P$-value \\
\hline Vitamin A (\%) & $\mathrm{RNI}$ & $120.5 \pm 48.1$ & $132.0 \pm 61.4$ & $103.2 \pm 72.0$ & 1.958 & 0.058 \\
\hline Vitamin D (\%) & $\mathrm{Al}$ & $71.3 \pm 34.1$ & $73.3 \pm 41.5$ & $68.8 \pm 60.9$ & 0.361 & 0.720 \\
\hline Vitamin $E(\%)$ & $\mathrm{Al}$ & $170.4 \pm 147.5$ & $190.9 \pm 216.7$ & $129.0 \pm 44.3$ & 1.731 & 0.092 \\
\hline Vitamin C (\%) & $\mathrm{RNI}$ & $85.0 \pm 32.7$ & $92.6 \pm 37.8$ & $70.1 \pm 35.2$ & 3.698 & 0.001 \\
\hline Vitamin $B_{1}(\%)$ & $\mathrm{RNI}$ & $114.8 \pm 26.7$ & $117.1 \pm 33.4$ & $109.3 \pm 32.2$ & 1.145 & 0.260 \\
\hline Vitamin $B_{2}(\%)$ & $\mathrm{RNI}$ & $80.8 \pm 20.8$ & $85.9 \pm 23.9$ & $77.5 \pm 32.2$ & 1.330 & 0.192 \\
\hline Niacin (\%) & $\mathrm{RNI}$ & $100.2 \pm 20.5$ & $103.6 \pm 25.1$ & $94.0 \pm 40.6$ & 1.162 & 0.253 \\
\hline Folic acid (\%) & $\mathrm{RNI}$ & $120.5 \pm 29.4$ & $125.1 \pm 37.2$ & $110.9 \pm 38.9$ & 1.686 & 0.101 \\
\hline $\mathrm{Ca}(\%)$ & $\mathrm{RNI}$ & $62.5 \pm 19.5$ & $67.2 \pm 20.9$ & $53.7 \pm 30.3$ & 2.606 & 0.013 \\
\hline$P(\%)$ & $\mathrm{RNI}$ & $103.6 \pm 22.2$ & $109.7 \pm 27.7$ & $91.4 \pm 37.2$ & 2.370 & 0.023 \\
\hline $\mathrm{Fe}(\%)$ & $\mathrm{RNI}$ & $119.8 \pm 31.8$ & $125.8 \pm 37.2$ & $109.7 \pm 49.3$ & 1.752 & 0.089 \\
\hline $\operatorname{Zn}(\%)$ & $\mathrm{RNI}$ & $133.5 \pm 33.4$ & $134.9 \pm 36.3$ & $129.9 \pm 58.4$ & 0.468 & 0.643 \\
\hline
\end{tabular}

Values are presented as mean \pm standard deviation.

$\mathrm{RNI}$, recommended nutrient intake; $\mathrm{Al}$, adequate intake.

alPercentage compared to the dietary reference intakes for Koreans (Ministry of Health and Welfare, Korean Nutrition Society, 2015).

Table 5. Comparison of the frequencies of intakes under the estimated average requirement (EAR) between weekdays and weekends $(n=72)$

\begin{tabular}{|c|c|c|c|c|c|c|}
\hline Nutrients & $E A R^{\text {a) }}$ & Total|b) & Weekdays ${ }^{c \mid}$ & Weekends $^{\mathrm{d} l}$ & $\chi^{2}$ value & $P$-value \\
\hline Protein (g/day) & $45 / 50$ & $0(0)$ & $0(0)$ & $7(19.4)$ & 7.754 & $0.011^{\mathrm{e})}$ \\
\hline Vitamin A ( $\mu \mathrm{g}$ RAE/day) & $540 / 620$ & $5(13.9)$ & $4(11.1)$ & $15(41.7)$ & 8.651 & $0.003^{\dagger}$ \\
\hline Vitamin C (mg/day) & $70 / 80$ & $13(36.1)$ & $10(27.8)$ & $19(52.8)$ & 4.677 & 0.031 \\
\hline Vitamin $B_{1}$ (mg/day) & $1.0 / 1.1$ & $5(13.9)$ & $3(8.3)$ & $8(27.2)$ & 2.683 & 0.101 \\
\hline Vitamin $B_{2}$ (mg/day) & $1.2 / 1.4$ & $20(55.6)$ & $21(58.3)$ & $19(52.8)$ & 0.225 & 0.635 \\
\hline Niacin (mg NE/day) & $11 / 13$ & $1(2.8)$ & $13(36.1)$ & $9(25.0)$ & 1.047 & 0.306 \\
\hline Folic acid ( $\mu \mathrm{g}$ DFE/day) & $300 / 320$ & $2(5.6)$ & $4(11.1)$ & $7(19.4)$ & 0.966 & 0.326 \\
\hline $\mathrm{Ca}$ (mg/day) & $800 / 720$ & 31 (86.1) & $27(75.0)$ & $32(88.9)$ & 2.347 & 0.126 \\
\hline $\mathrm{P}$ (mg/day) & 1,000 & $4(11.1)$ & $2(5.6)$ & $19(52.8)$ & 19.429 & 0.000 \\
\hline $\mathrm{Fe}$ (mg/day) & 11 & $2(5.6)$ & $2(5.6)$ & $12(33.3)$ & 8.867 & 0.003 \\
\hline $\mathrm{Zn}$ (mg/day) & $7 / 8$ & $2(5.6)$ & $2(5.6)$ & $9(25.0)$ & 5.258 & 0.022 \\
\hline
\end{tabular}

RAE, retinol activity equivalents; NE, niacin equivalent; DFE, dietary folate equivalent.

a)EAR from dietary reference intakes for Koreans (Ministry of Health and Welfare, Korean Nutrition Society, 2015). Values are presented as male 12-14 yr/15-18 yr. ${ }^{\text {b-d }}$ Values

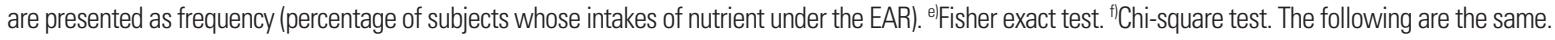




\section{DISCUSSION}

In this study, an analysis of the dietary intake patterns of male middle- and long-distance athletes aged 13-18 years revealed very low daily energy intake, $2,051.0 \pm 304.3 \mathrm{kcal}$. This was much lower than the EER of male adolescents in the 2015 KDRI, which suggests 2,500 kcal per day for most 12-14 year olds and 2,700 kcal per day for most $15-18$ year olds and only $60.7 \%$ of the EER for very active people of same age. This was also lower than the daily energy intake of 2,391.1 $\pm 77.3 \mathrm{kcal} /$ day of Korean male teenagers (12-18 years old) reported in the 2017 Korea National Health and Nutrition Examination Survey (Ministry of Health and Welfare, Korea Centers for Disease Control and Prevention, 2018).

The physique development of the athletes, which is closely related to the energy balance, was $170.9 \mathrm{~cm}$ in height $(52.3$ percentile), $55.7 \mathrm{~kg}$ in weight (25.1 percentile), and $19.0 \mathrm{~kg} / \mathrm{m}^{2}$ in BMI (16.8 percentile), showing a very thin body compared to adolescents of the same age. Adequate energy intake is important for healthy growth and athletic performance. Moreover, other nutrients are more likely to be supplied at the required levels when appropriate amounts of energy are consumed.

Protein was consumed at $136.3 \% \pm 32.7 \%$ of the recommended nutrient intake in our participants. The 2017 Korea National Health and Nutrition Examination Survey shows that all age groups in Korea, including males aged 12 to 18 years, tended to consume more than the dietary reference intake of protein. Dietary proteins not only provide a substrate for muscle synthesis, but are essential for securing the structural stability and metabolic functions of nonmuscular tissues, such as bones and tendons. Athletes generally require a quantity of 1.2 to $2.0 \mathrm{~g} / \mathrm{kg}$ body weight/ day to support metabolic adaptation, recovery, and remodeling following training (Thomas et al., 2016). In this study, on average, athletes consumed approximately $1.4 \mathrm{~g} / \mathrm{kg}$ body weight/day of protein.

The nutrients that showed much lower levels than the dietary reference intake were vitamin $\mathrm{D}$, vitamin $\mathrm{C}$, vitamin $\mathrm{B}_{2}$, and calcium. Of the nutrients examined, $86.1 \%$ of athletes consumed less than the EAR of calcium, which was the highest ratio. More than half of the athletes (55.6\%) were taking lower levels of riboflavin than the EAR and $36.1 \%$ were consuming vitamin $\mathrm{C}$ at a lower level than the EAR. The report from the 2017 Korean National Health and Nutrition Examination Survey (Ministry of Health and Welfare, Korea Centers for Disease Control and Prevention, 2018) showed that, as in this study, the intake of calcium and vitamin $\mathrm{C}$ in male adolescents was much lower than the di- etary reference intake, but the intake of riboflavin was $116.6 \%$ of the KDRI, which was different from the $80.8 \%$ observed in this study.

Riboflavin contributes to oxidative energy production in the mitochondrial electron transport system and is found in various foods, such as pork, milk and dairy products, eggs, and fish. Therefore, it is generally reported that riboflavin deficiencies are rare when sufficient food is consumed, and athletes with limited food intake are more likely to show a shortage of riboflavin (Lukaski, 2004). In this regards, the low intake of riboflavin in this study seems to be related to the low energy intake of the athletes.

Calcium and vitamin $\mathrm{D}$ are very important nutrients for adolescent athletes. Calcium plays a critical role in bone development, muscle contractions, and neurotransmission. Moreover, vitamin D has an important function in maintaining bone health and controlling the absorption and metabolism of calcium and phosphorus (Rizzoli et al., 2010; Thomas et al., 2016). The interest in vitamin D has increased considerably in recent years and its relevance to rehabilitation, stress fractures, nervous function, muscle size, and inflammation has been reported (Desbrow, 2014; Thomas et al., 2016). Despite the important functions of calcium and vitamin $\mathrm{D}$, athletes are generally deficient in these nutrients (Gibson et al., 2011; Juzwiak et al., 2008; Martínez et al., 2011; Powers et al., 2011). Although dietary vitamin $\mathrm{D}$ intake is inadequate, the risk of vitamin $\mathrm{D}$ deficiency might be in lower in runners because of their exposure to sufficient ultraviolet irradiation from the large amount of outdoor activity. Therefore, athletes will need to undergo physiological examinations to make a more accurate evaluation regarding vitamin $\mathrm{D}$ deficiency.

In this study, the vitamin $C$ intake was also low and decreased significantly on weekends. Vitamin $\mathrm{C}$ is one of the nutrients that the average teenager in Korea generally takes in low levels. It plays an important role in the synthesis of catecholamine and carnitine needed to transport the long-chain fatty acids to the mitochondria, promoting the uptake of non-heme iron in the mucous membranes, and protecting the cell membranes from oxidative damage (Lukaski, 2004). Therefore, a vitamin $C$ deficiency can lead to fatigue, muscle weakness, anemia, and slow recovery from excessive training.

In conclusion, adolescent male middle- and long-distance runners have very low energy intake and deficient calcium, vitamin $\mathrm{B}_{2}$, vitamin $\mathrm{C}$ and vitamin $\mathrm{D}$, with a very skinny body for their age. As the intake of calcium and vitamin $\mathrm{C}$, along with some nutrients, is significantly reduced on weekends, appropriate management should be taken not only for weekday meals at school, but 
also for home foods and eating out on weekends.

To improve these nutrition conditions, not only athletes, but also coaches and parents need to be educated on the appropriate nutrition intake of athletes during their growth period. To develop effective strategies for improving the nutritional status of adolescent athletes, further research will be needed to examine the nutritional awareness and knowledge of athletes, coaches, and parents.

\section{CONFLICT OF INTEREST}

No potential conflict of interest relevant to this article was reported.

\section{REFERENCES}

Aerenhouts D, Deriemaeker P, Hebbelinck M, Clarys P. Energy and macronutrient intake in adolescent sprint athletes: a follow-up study. J Sports Sci 2011;29:73-82.

Desbrow B, McCormack J, Burke LM, Cox GR, Fallon K, Hislop M, Logan R, Marino N, Sawyer SM, Shaw G, Star A, Vidgen H, Leveritt M. Sports Dietitians Australia position statement: sports nutrition for the adolescent athlete. Int J Sport Nutr Exerc Metab 2014;24:570-584.

Gibson JC, Stuart-Hill L, Martin S, Gaul C. Nutrition status of junior elite Canadian female soccer athletes. Int J Sport Nutr Exerc Metab 2011;21: 507-514.

Juzwiak CR, Amancio OM, Vitalle MS, Pinheiro MM, Szejnfeld VL. Body composition and nutritional profile of male adolescent tennis players. J Sports Sci 2008;26:1209-1217.
Lukaski HC. Vitamin and mineral status: effects on physical performance. Nutrition 2004;20:632-644.

Martínez S, Pasquarelli BN, Romaguera D, Arasa C, Tauler P, Aguiló A. Anthropometric characteristics and nutritional profile of young amateur swimmers. J Strength Cond Res 2011;25:1126-1133.

Meyer F, O'Connor H, Shirreffs SM; International Association of Athletics Federations. Nutrition for the young athlete. J Sports Sci 2007;25 Suppl 1:S73-82

Ministry of Health and Welfare, Korea Centers for Disease Control and Prevention. Korea Health Statistics 2017: Korea National Health and Nutrition Examination Survey (KNHANES VII-2). Cheongju (Korea): Korea Centers for Disease Control and Prevention; 2018.

Ministry of Health and Welfare, Korean Nutrition Society. Dietary reference intakes for Koreans. Sejong (Korea): Ministry of Health and Welfare; 2015.

Petrie HJ, Stover EA, Horswill CA. Nutritional concerns for the child and adolescent competitor. Nutrition 2004;20:620-631.

Powers S, Nelson WB, Larson-Meyer E. Antioxidant and Vitamin D supplements for athletes: sense or nonsense? J Sports Sci 2011;29 Suppl 1: S47-55.

Rizzoli R, Bianchi ML, Garabédian M, McKay HA, Moreno LA. Maximizing bone mineral mass gain during growth for the prevention of fractures in the adolescents and the elderly. Bone 2010;46:294-305.

Solomon ML, Briskin SM, Sabatina N, Steinhoff JE. The pediatric endurance athlete. Curr Sports Med Rep 2017;16:428-434.

Thomas DT, Erdman KA, Burke LM. American College of Sports Medicine Joint Position Statement. Nutrition and athletic performance. Med Sci Sports Exerc 2016;48:543-568. 